\title{
The selection hypothesis of social inequalities in health: The Oslo Mortality Study
}

\author{
Bjørgulf Claussen and Øyvind Næss
}

\author{
Institute of General Practice and Community Medicine, Department of Work and Social Insurance Medicine, \\ University of Oslo, Norway \\ Correspondence to: Bjørgulf Claussen, Institute of General Practice and Community Medicine, Department of Work and Social \\ Insurance Medicine, P.O. Box 1130 Blindern, N-0317 Oslo, Norway \\ Telephone: +4722850550 Telefax +4722850610 E-mail: bjorgulf.claussen@samfunnsmed.uio.no
}

\begin{abstract}
We wanted to use the possibilities of Norwegain statistics to test if health-related mobility explains some of the social inequalities in mortality, the so-called selection hypothesis. Premature death was regarded as an expression of health potentials at a group level. Social mobility was followed by the occupation of all employed Oslo inhabitants in the age group 20-39 years in 1960 to their occupation at the age of 40-59 years in 1980. Deaths were registered at the age of 50-74 in 1990-94. We found that those moving upwards in the social hierachy had lower mortality than their class of origin, supporting the selection hypothesis, but higher mortality than their class of destination, contradictory to the hypothesis. As expected, the oppostite pattern was found for downward mobility. The analysis is not finished. We will try to calculate the net effect of social mobility on the cross-sectional inequalities in mortality in Oslo.
\end{abstract}

After the Black report in 1981 documented increasing differences in mortality between the social classes in post-war Western countries, the reasons for these differences have been vividly discussed (1). Most researchers today believe that social class differences in health are mostly explained by the living conditions of different classes, so-called social causation (2). Some stick to the opinion that health-related selection of young people to their middle age class position may play an important role in our societies where both upand downward social mobility seem to be prevalent (3). Figures are scarce, however, due to lack of longterm follow-ups $(4,5)$.

\section{THE SELECTION HYPOTHESIS}

This explanation of social inequalities in health implies, first, that those moving upwards in the social hierarchy have better health potentials than stable persons in the class of destination, and vice versa for downward mobility (figure 1). We call this mechanism inflow mobility because the focus is health-related mobility into each class. Second, the cross-sectional picture is patterned by outflow mobility, i.e. the selection hypothesis implies that those moving upwards have better health potentials than stable persons in the class of origin, and vice versa regarding downward mobility.

In the first period of inequality research, the selection hypothesis was merely tested by inflow mobility $(1,2)$. But, as Elstad (4) and Blane (5) have shown, if inflow and outflow mobility work in different directions, the net results of social mobility on health inequalities will be an empirical issue.

The selection hypothesis has been tested by following sick young adults with meagre results (6). The explanation may be that there are few young adults with obviously poor health. A more relevant and realistic design has been to measure self-reported general health at two points in time, and follow health-related selection (4). Such data are difficult to obtain for a large population over a certain period of time.
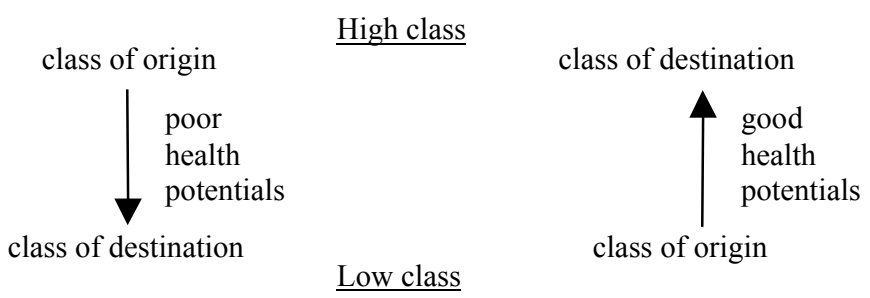

Figure 1. A model of the selection hypothesis with only two classes showing inflow and outflow social mobility related to health potentials. 


\section{THE PRESENT STUDY}

Our design is to consider premature death as a proxy for health potentials at the entrance of adult life. Hypothetically, health potentials may be physical, emotional and intellectual strength, social abilities, push and pull traits, and so on. Surviving the age of 69 is then taken as an expression of good health potentials. Often, this is not correct at an individual level, but is worth considering on an aggregate level.

The aim of the present article is to use the possibilities of Norwegian statistics to determine the impact of intragenerational social mobility in the period 1960 to 1980 on class specific mortality in 1990 to 1994 .

\section{Subjects and methods}

The material was all the 88,159 persons in the age of 50 to 69 years who lived in the municipality of Oslo on January 1, 1990. This sample was chosen because they were young adults in 1960 starting their occupational careers, and old enough in 1990-94 to have some deaths, in all 6,727 fatalities in this five-year period. Census data from 1960, 1970 and 1980 were linked with the Death Register for 1990-94.

Dependent variable was the mortality in the five years 1990-94. All death certificates are registered with Statistics Norway without any missing cases.

Occupation was ordered by the Erikson-Goldthorpe scheme in the following seven classes (7):

I Professionals and salaried employees on a high level II Lower level professionals, medium level employees and high level technicians

III Low level employees

IVabd Self-employed

IVc Farmers and self-employed fishermen

V/VI Low level technicians, foremen, skilled workers

VII Unskilled workers, farm and fishery labourers

We lacked some variables for this scheme implying that the 3,315 self-employed and the 443 farmers could not be placed in the social hierarchy. However, they comprised only $4.4 \%$ of the 81,572 economically active inhabitants in the cohort in 1980, and fewer in 1960 when the cohort was younger.

In the main analyses only employed persons were included. We summed low level employees (class III) and skilled labour (class V/VI) because moves between these two classes usually did not mean any movement of social position or economic output in Norway for the last 40 years.

Married women were placed in the social class of their husband if he was or had been economically active, since recent research from Norway has shown that this procedure gives the best correlation between health and social class (8).

Persons reporting to be pensioners at the Census were put in their last occupation in order to diminish the "healthy worker" effect on mortality (9). The remaining ones were also pensioners in 1960.

Students were primarily those who were registered as such in the Education Register. If they reported having a job at the Census, they were still registered as students if they were under 25 years of age, but employed if they were older. This schematic classification implied that some older students with part time service or manual work were placed in a lower social class than is realistic as for their future career, but no more than $0.3 \%$ of all students in the 1960 sample aged 2039 reported having an occupation.

"Staying at home" was the status of a person reporting that the main source of living was the income of another person if $\mathrm{s} / \mathrm{he}$ was not registered as a student or a pensioner.

\section{Missing data}

Answering the Census is obligatory by law, and no missing schemes were reported. Some did not live in Norway from 1960 to 1990 , however, and some did not answer all questions, giving $9.8 \%$ missing values for the actual answers from 1960. Then, non-responders were much more often from oversea countries ( $14.4 \%$ vs. $0.1 \%$ of the responders) or from other West-European countries $(17.0 \%$ vs. $1.1 \%)$, and more rarely from Norway ( $68.6 \%$ vs. $98.8 \%$ among responders). The smaller number of missing values of employment status in 1980 had practically speaking the same distribution. Mortality rates were lower than for the responders, indicating that low social status was not especially prevalent among the non-responders (Table 1). This means that the study is fairly representative for citizens of Norwegian origin living in Oslo in 1990.

\section{Statistics}

Logistic regressions were used to give age-adjusted odds ratios which are not much biased since mean mortality rates during five years were $10.2 \%$ for men and $5.5 \%$ for women.

\section{Results}

Table 1 shows crude mortality rates 1990-94, when the cohort was from 50 to 74 years of age, according to employment status in 1980 (age 40 to 59). The small groups of prevailing pensioners had the highest mortality, followed by those staying at home. The seven classes being at work in 1980 (or having been before getting a pension) had in general higher mortality rates with decreasing social class for both genders. Exceptions were the two classes IV of self-employed which cannot be ordered hierachically. Odds ratio for 1980 class I compared to class VII was 0.51 for men and 0.62 for women. The same figure was 0.75 by 1960 class position for both genders.

Table 2, and more clearly Table 3 , shows mortality rates by social mobility adjusted for age.

Outflow mobility contributes to increased mortality in the classes of origin because upward movers had considerably lower mortality than the class of origin, i.e. according to the selection hypothesis. 
Table 1. Mortality 1990-94 (per 10,000 person-years) among 50-69 years old inhabitants in Oslo 1.1 .90 by employment status 1980 .

\begin{tabular}{lrrrrrr}
\hline & \multicolumn{2}{c}{ Women } & & \multicolumn{3}{c}{ Men } \\
\cline { 2 - 3 } \cline { 7 - 8 } Status 1980 (40-59 years of age) & Mortality & $(\mathrm{n})$ & & Mortality & (n) \\
\hline Class I (high salaried employees) & 86 & $(9379)$ & & 144 & $(9005)$ \\
Class II (medium level emplyees) & & 88 & $(9284)$ & & 176 & $(7503)$ \\
Class III (low level employees) & 112 & $(11834)$ & & 212 & $(5477)$ \\
Class V/VI (skilled workers) & 126 & $(6430)$ & & 230 & $(6615)$ \\
Class VII (unskilled workers) & 138 & $(6669)$ & & 280 & $(5818)$ \\
Sum employed & 110 & $(43596)$ & & 218 & $(34418)$ \\
Self-employed (class IVabd and IVc) & 120 & $(973)$ & & 193 & $(2585)$ \\
Staying at home, students & 162 & $(1435)$ & & 144 & $(1595)$ \\
Pensioners (no jobs 1960, 1970 or 1980) & 282 & $(405)$ & & 466 & $(223)$ \\
Missing status & 64 & $(1267)$ & & 136 & $(1712)$ \\
Sum all & 110 & $(47626)$ & & 204 & $(40533)$ \\
\hline
\end{tabular}

Table 2. Mortality rates $1990-94$ among $50-69$ years old inhabitants in Oslo 1.1 .90 by social mobility from 1960 to 1980 according to occupation, controlled for age in logistic regressions. Odds ratios, significance levels, participants and number of deaths in each combination of 1980 and 1960 class.

\begin{tabular}{|c|c|c|c|c|c|c|c|c|c|}
\hline \multirow{2}{*}{$\begin{array}{l}\text { Class* } \\
1980\end{array}$} & \multirow[b]{2}{*}{1960} & \multicolumn{4}{|c|}{ Men } & \multicolumn{4}{|c|}{ Women } \\
\hline & & $\mathrm{n}$ & Deaths & OR & Sign\# & $\mathrm{n}$ & Deaths & OR & Sign\# \\
\hline \multirow[t]{4}{*}{ Class I } & Class I & 2637 & 219 & .43 & .000 & 913 & 47 & .79 & .135 \\
\hline & Class II & 2006 & 143 & .40 & .000 & 1656 & 52 & .48 & .000 \\
\hline & Class III/V/VI & 2326 & 193 & .55 & .000 & 2421 & 88 & .58 & .000 \\
\hline & Class VII & 373 & 25 & .46 & .000 & 1834 & 83 & .63 & .000 \\
\hline \multirow[t]{4}{*}{ Class II } & Class I & 685 & 58 & .45 & .000 & 605 & 23 & .60 & .019 \\
\hline & Class II & 2414 & 222 & .51 & .000 & 2257 & 99 & .65 & .000 \\
\hline & Class III/V/VI & 2414 & 214 & .57 & .000 & 2685 & 100 & .58 & .000 \\
\hline & Class VII & 869 & 95 & .70 & .004 & 2466 & 118 & .68 & .000 \\
\hline \multirow[t]{4}{*}{ Class III/V/VI } & Class I & 627 & 87 & .77 & .037 & 760 & 35 & .69 & .040 \\
\hline & Class II & 885 & 96 & .64 & .000 & 1366 & 65 & .68 & .005 \\
\hline & Class III/V/VI & 7268 & 855 & .71 & .000 & 7395 & 432 & .88 & .072 \\
\hline & Class VII & 2273 & 248 & .70 & .000 & 8897 & 535 & .81 & .001 \\
\hline \multirow[t]{4}{*}{ Class VII } & Class I & 291 & 35 & .69 & .051 & 154 & 13 & 1.37 & .293 \\
\hline & Class II & 554 & 89 & .98 & .880 & 165 & 6 & .58 & .190 \\
\hline & Class III/V/VI & 1626 & 221 & .86 & .082 & 1544 & 97 & 1.02 & .867 \\
\hline & Class VII & 3031 & 477 & 1.00 & - & 6652 & 512 & 1.00 & - \\
\hline Sum & & 30279 & 3277 & & & 41770 & 2305 & & \\
\hline
\end{tabular}

* Categorical class variables

\# P value of difference from the reference category

Table 3. Age-adjusted odds ratios of mortality 1990-94 by social mobility from 1960 to 1980.

\begin{tabular}{|c|c|c|c|c|c|c|c|c|}
\hline \multirow[b]{3}{*}{1960 class (20-39 years) } & \multicolumn{8}{|c|}{1980 class ( $40-59$ years) } \\
\hline & \multicolumn{4}{|c|}{ Men } & \multicolumn{4}{|c|}{ Women } \\
\hline & $\mathrm{I}$ & II & $\mathrm{III} / \mathrm{V} / \mathrm{VI}$ & VII & $\mathrm{I}$ & II & $\mathrm{III} / \mathrm{V} / \mathrm{VI}$ & VII \\
\hline I & .43 & .45 & .77 & $.69^{\mathrm{ns}}$ & $.79^{\mathrm{ns}}$ & .60 & .69 & $1.37^{\mathrm{ns}}$ \\
\hline II & .40 & .51 & .64 & $.98^{\mathrm{ns}}$ & .48 & .65 & .68 & $.58^{\mathrm{ns}}$ \\
\hline $\mathrm{III} / \mathrm{V} / \mathrm{VI}$ & .55 & .57 & .71 & $.86^{\mathrm{ns}}$ & .58 & .58 & .88 & $1.02^{\mathrm{ns}}$ \\
\hline VII & .46 & .70 & .70 & 1.00 & .63 & .68 & .81 & 1.00 \\
\hline
\end{tabular}

${ }^{n s}$ Non-significant difference from the reference category $(\mathrm{p}>0.05)$ 
Inflow mobility did not follow the expected pattern, however. Grossly speaking, mortality for the persons moving upwards was higher than in the class of destination, not lower as expected.

For women, the pattern was less clear than for men. Moving down into class VII seemed to be accociated with high mortality, and moving up into class I was associated with lower mortality than for stable class I women, as expected from the selection hypothesis. The mortality rate for the small group of stable class I women was extraordinarily high, however, and otherwise the hypothesis was only supported by the female data of outflow mobility as for the males.

\section{DiscuSSION}

Our data support the selection hypothesis as for outflow mobility but not for the more discussed inflow mobility $(1,2)$. We do not find what some researchers have hypothesised, that the higher social classes are supplied with extra healthy people climbing up from the lower classes (3). Then, the summed effect of social mobility on the cross-sectional inequalities in health is an empirical question. Whether social mobi- lity constrains or widens health inequalities depends on how closely mobility is related to health, the magnitude of mobility, and the cross-sectional divides in health (4).

Our results are in full accordance with Elstad's study of self-reported chronic illness in the Norwegian Level of Living Surveys (4). In his study, social mobility during 20 years from age 20-39 to age 40-59 contributed to constrict social inequalities.

The same was found by Blane and coworkers in an analysis of mortality in the National Statistics Longitudinal Study with data in 1971 and 1981 of 46,980 British men aged 45-64 (5). We can confirm this British study for about the same age group of both Norwegian men and women over a longer span of time.

Now we want to calculate the net effect of social mobility on the cross-sectional distribution of death across social position. We have not done that yet because we are looking for appropriate methods of summing 1-3 steps up and 1-3 steps down for both inflow and outflow mobility. We plan to use a method called the Diagonal Reference Model developed by a group of Dutch demographers at the National Institute of Public Health and the Environment (10), but we are open for other proposals.

\section{REFERENCES}

1. Wilkinson RG. Social determinants of health. Oxford: Oxford University Press, 1999.

2. Dahl E. Social inequalities in health: cause or effect? (editorial). BMJ 1996; 313: 435-6.

3. West P. Rethinking the health selection explanation for health inequalities. Soc Sci Med 1991; 32: 373-84.

4. Elstad JI. Health-related mobility, health inequalities and gradient constraint: discussion and results from a Norwegian study. Eur J Public Health 2001; 11: 135-40.

5. Blane D, Harding S, Rosato M. Does social mobility affect the size of the socioeconomic mortality differentials?: evidence from the Office for National Statistics Longitudinal Study. J R Stat Soc 1999; 162: 59-77.

6. Roberts H. Children, inequalities, and health. BMJ 1997; 314: 122-5.

7. Erikson R, Goldthorpe J. The constant flux. Oxford: Clarendon Press, 1992.

8. Dahl E. Inequality in health and the class position of women - the Norwegian experience. Sociol Health Illness 1991; 13: 492-505.

9. Dahl E. Inequality in health - the role of the healthy worker effect. Soc Sci Med 1993; 36: 1077-86.

10. Smits J, Ultee W, Lammers J. Educational homogamy in 65 countries: An explanation of differences in openness using country-level explanatory variables. Am Sociol Rev 1998; 63: 264-85. 